\title{
CHEMICAL U-Th-Pb GEOCHRONOLOGY: A PRECISE EXPLICIT APPROXIMATION OF THE AGE EQUATION AND ASSOCIATED ERRORS
}

\author{
GAVRIL SĂBĂU \\ Geological Institute of Romania, 1 Caransebeş st., RO-012271 Bucharest 32, Romania
}

Received 23 March 2011

Accepted 2 April 2012

\begin{abstract}
In a single decaying system, the age determined from the exponential decay law is directly related to its linear Maclaurin approximation. This relationship can be additively extended to several decaying systems resulting in the same daughter element, by using proportionality functions, thus allowing an explicit formulation of the age as a function of element concentrations. The values of the binary proportionality function for the ${ }^{238} \mathrm{U}-{ }^{235} \mathrm{U}-\mathrm{Pb}$ system and the ternary proportionality function for the ${ }^{232} \mathrm{Th}-238 \mathrm{U}-{ }^{235} \mathrm{U}-\mathrm{Pb}$ system were determined by iterations of the exponential decay formula up to $4 \mathrm{Ga}$, with a step of $10 \mathrm{Ma}$, for a set of 24 different U/Th ratios. From the iteration data, the expressions of the two functions and the associated coefficients were determined by polynomial regression and mathematical programing on conveniently separated time and compositional intervals.

Additional time- and composition-dependent age corrections optimized by mathematical programming of the residuals lead to an accuracy of $0.005 \mathrm{Ma}$ of the resulting age. The error propagation can be traced through all the operations defined by explicit formulas according to simple error propagation rules, finally allowing the calculation of the standard error of the result. The formulas and parameters derived can be used in a calculation spreadsheet.
\end{abstract}

Keywords: $\mathrm{U}-\mathrm{Th}-\mathrm{Pb}$ chemical dating, age equation, explicit approximation.

\section{INTRODUCTORY REMARKS}

Chemical U-Th-Pb geochronology has increasingly revealed during the last decades its wide potential and applicability (e. g. Williams et al., 2006; Suzuki and Kato, 2008). At the present day, it is unrivalled among the geochronological methods at least by its non-destructive nature, high spatial resolution, truly in situ character, and low costs as compared to isotopic methods. Microprobe analysis of metamorphic radioactive mineral grains not only provide accurately localized analyses on the surface of a particular grain, but also allows investigation of entire texturally referenced populations in their original setting in the rock sample.
The inherent drawbacks are related to the fact that a chemical method is targeted to study isotopic systems, which can lead to reasonable results only if some simplifying assumptions about the behaviour of these systems hold true, and the generally lower sensitivity as compared to the isotopic methods. Even though, chemical U-Th- $\mathrm{Pb}$ geochronology progressively appears to be the ideal method applicable to metamorphic rocks, because of the widespread and common character of the potential target phases (especially monazite, but also brabantite, rhabdophane, xenotime, thorite/huttonite), coupled with very low diffusion rates in these phases, and consequently extensive growth below the isotopic blocking temperature.

Corresponding author: G. Săbău

e-mail:g_sabau@yahoo.co.uk 
The key simplifying assumptions of the method are that all measured lead is radiogenic, or the primary lead incorporated can be quantified during data processing, and limited intra-crystalline diffusion occurs in the target mineral after its formation, thereby ensuring preservation of isotopic equilibrium. Though attempts to quantify and compensate for common lead are noteworthy (Kato et al., 1999), and the corresponding pseudo-isochron approach is actually the source of the most circulated acronym for the method, CHIME (CHemical Isochron MEthod - Suzuki et al., 1991), both analyzed (Parrish, 1990) and calculated (Rhede et al., 1996; Suzuki, 2009) common lead in monazite resulted to be insignificant when compared to radiogenic $\mathrm{Pb}$. On the other hand, diffusion rates in the monazite structure are extremely low, corresponding to very high blocking temperatures (Cherniak et al., 2004). Resetting of the original monazite composition may occur, however, during subsequent fluid-driven corrosion, infiltration and dissolution-reprecipitation (Bosse et al., 2009). In these cases, Williams et al. (2011) notice that fluid-aided alteration of monazite results in complete resetting of the isotopic system, with total removal of $\mathrm{Pb}$ from the monazite lattice.

The intrinsic difficulties in measuring trace-elements with the microprobe raise several precision and accuracy issues. Since the early years of its application (Suzuki et al., 1991; Montel et al., 1994), various particular aspects of the analytical technique were addressed in order to control a large number of drawbacks and interfering factors, starting from sample contamination during preparation (Scherrer et al., 2000), matrix effect, choice of analytical conditions for an acceptable compromise between peak-background ratio and beam-irradiation effects, assessment and compensation of background levels and acquisition interferences (Pyle et al., 2005; Jercinovic and Williams, 2005; Jercinovic et al., 2008). The increased knowledge resulting from such studies lead to significant progress towards coherent work protocols (e.g. Williams et al., 2006; Suzuki and Kato, 2008) and the application of the method in a continuously growing number of laboratories world-wide, using various types of equipment (Slagstad, 2006; Vlach, 2010). Nonetheless, the importance of setting up customized working procedures, conditions and correction factors according to the available equipment was clearly asserted by Vlach (2010).

Element concentrations are in common use converted to age values according to a $\mathrm{Pb}$-balance equation (in weight units) outlined by Montel et al. (1996):

$$
\begin{aligned}
& P b=\frac{T h}{A_{232}}\left(e^{\lambda_{232} t}-1\right) \times A_{208}+\frac{U}{A_{U}} \times 0.9928 \times \\
& \left(e^{\lambda_{238} t}-1\right) \times A_{206}+\frac{U}{A_{U}} \times 0.0072 \times\left(e^{\lambda_{235 t}}-1\right) \times A_{207}
\end{aligned}
$$

where $A_{n}$ stands for the atomic masses of the respective isotopes/elements, and the lead-balance equation assumes no common lead. The above-mentioned approach has the advantage of being independent of the unknown atomic mass of radiogenic lead, but its downside is that the time value is implicit and can be derived only by iteration. Consequently, the error propagation from analytical to time errors in single-point analyses cannot be traced rigorously, allowing only estimates often with questionable reliability. In most cases, the evaluation of the errors are undertaken by undisclosed procedures (Montel et al., 1996) or by empirical propagation through the iterated formula, as currently done in several laboratories by using calculation spreadsheets assisted by macro routines, or even stand-alone software. More accurate, though not largely applied assessments of the error propagation from element concentrations to age values involve Monte Carlo simulation (Lisowiec, 2006; Vlach, 2010) or propagation of the errors through an explicit approximation of the age equation by the second-order Maclaurin expansion (Vlach, 2010). Notwithstanding significant progress achieved by these latter approaches, they are still biased by certain setbacks. Monte Carlo simulations deliver reliable results, but might prove prohibitive for the untrained user because of the complexity of the operations involved. On the other hand, the precision of the errors determined by Maclaurin expansion of the age equation significantly decline with the age of the sample, requiring the use of increasingly difficult to handle higher-order expansions.

Bearing in mind that in statistical handling of data, the computed individual values, including their errors, should be as precise and clearly defined as possible, error handling based on explicit equations and complying with the error propagation rules qualify as the best option for characterizing age populations. An alternative approach, based on repeated measurements on a compositional domain assumed to be homogeneous, the "bottom-up" analysis of Williams et al. (2006), calculation of the average and subsequent statistical handling of the entire population, appears to be affected by the actual degree of homogeneity of the selected domain, and the number of measurements (Lisowiec, 2006).

In order to overcome these difficulties and allow a straightforward estimation of the errors associated to single-point analyses, an alternative procedure is outlined hereinafter, according to which an explicit expression of the age equation is derived, based on correction functions applied to the first-order Maclaurin expansion. The parameters of these functions are constrained from multiple regression and mathematical programming of precise iteration data, and the associated errors are calculated by stepwise propagation through explicit formulations, from microprobe data to age values. A preliminary account of the method was given in Săbău (2009).

Approximating age values from indirect measurements like chemical or dosimetric analyses by using empirical formulations and correction factors in explicit expressions has represented a common procedure since the beginning of isotopic geochronology (Geyh and 
Schleicher, 1990, and refs. therein); the precision and range of the formulae was limited by the number of the coefficients used, in such a way that higher precision and wider ranges would result in fastidious calculations. Automatic calculus, on the other hand, allows the determination and storage of as large a number of parameters as required to obtain the desired precision, which are to be derived only once and then used as such every time needed. Consequently, the derivation and refinement of the correction functions and parameters, associated with the explicit calculation of the U-Th- $\mathrm{Pb}$ radiogenic ages from measured element concentrations and associated errors was aimed to a precision level of $0.005 \mathrm{Ma}$, up to $4 \mathrm{Ga}$, comparable to that obtained by iteration of the (radiogenic) lead-balance equation of Montel et al. (1996).

\section{THE APPROXIMATION OF THE AGE FOR- MULA}

Radioactive decay of radionuclides follows the exponential decay law, stating that the number of elements of a population undergoing an irreversible transition decreases at any moment by a quantity equalling the number of elements in the population multiplied by a constant related to the probability of that transition to spontaneously occur in the population:

$\frac{d N}{d t}=-\lambda N$.

In terms of radioactive decay, $\boldsymbol{N}$ is the number of atoms of the parent isotope, $\lambda$ the decay constant, and $t$ is time. By rearranging and integrating this expression,

$\int_{N_{0}}^{N} \frac{d N}{N}=-\lambda \int_{0}^{t} d t$

one obtains:

$\ln \left(\frac{N}{N_{0}}\right)=-\lambda t$.

Because $N_{0}$, the initial number of parent atoms, equals the sum of the parent $(N)$ and daughter atoms $\left(N_{D}\right)$, this expression becomes $\mathrm{e}^{\lambda t}=\boldsymbol{N}_{D} / \boldsymbol{N}+\mathbf{1}$. A Maclaurin series expansion of the function $\mathrm{e}^{\lambda t}$ truncated after the second term renders $\mathrm{e}^{\lambda t} \approx 1+\lambda \mathrm{t}_{1}$, where the subscript index indicates the first-order Maclaurin approximation. Equalling

$t=\frac{137.88 f_{U} \ln \left(f_{U}+10^{6} \lambda_{238} t_{1}\right) / \lambda_{238}+\ln \left(1+10^{6} \lambda_{235} t_{1}\right) / \lambda_{235}}{10^{6}\left(137.88 f_{U}+1\right)}$ the two $\mathrm{e}^{\lambda t}$ formulations results in

$t_{1}=\frac{1}{\lambda} \frac{N_{D}}{N}$,

equivalent to $N_{D}=\lambda N t_{1}$. Under the crude assumption of matching $\boldsymbol{t}_{\boldsymbol{l}}$ values in independent decay systems leading to the same daughter-element $(\mathrm{Pb})$,

$t_{1}=\frac{1}{\lambda_{i}} \frac{N_{D_{i}}}{N_{i}}$,

$N_{D}=\sum N_{D i}=t_{1} \sum \lambda_{i} N_{i}$,

the time approximation becomes

$t_{1}=\frac{N_{D}}{\sum \lambda_{i} N_{i}}$,

which yields

$t_{1}=\frac{138.88 P b}{10^{6}\left(137.88 \lambda_{238}+\lambda_{235}\right) U}$

for the $\mathrm{U}-\mathrm{Pb}$ and

$t_{1}=\frac{10^{-6} P b}{\lambda_{232} T h+\left(137.88 \lambda_{238}+\lambda_{235}\right) U / 138.88}$

for the U-Th-Pb system, elements expressed in atomic proportions, ages in $\mathrm{Ma}$, and natural isotopic ratio of uranium according to Shields (1960).

The actual time value $\boldsymbol{t}$ can be written as a direct function of the approximated $\boldsymbol{t}_{1}$ value in any individual decay system: $\boldsymbol{t}=\ln \left(1+\lambda_{\mathrm{i}} \boldsymbol{t}_{1}\right) / \lambda_{\mathrm{i}}$. In a composite system with two or more parent isotopes decaying into isotopes of the same element, the linear combination of the $t v s$. $\boldsymbol{t}_{1}$ relationships doesn't hold true because of distinct deviations of individual $\boldsymbol{t}_{1}$ 's, both mutual and from the $\boldsymbol{t}$ value, but may be compensated by an empirical factor applied to the present elemental/isotopic ratios. For the U series, a proportionality function $\mathrm{f}_{\mathrm{U}}=\boldsymbol{f}\left(\boldsymbol{t}_{1}\right)$ may be introduced which ensures that the combination of the two decaying systems lie along a mixing line, $\mathrm{f}_{\mathrm{U}}$ also compensating for the previous simplifying assumption of matching $\boldsymbol{t}_{1}$ values in formula (2.8), which gives Equation 2.10.

Similarly, the compensation of the $\boldsymbol{t}_{1}$-bias in the U-Th$\mathrm{Pb}$ system is achieved by employing an additional factor $\mathrm{f}_{\mathrm{UTh}}=\boldsymbol{f}\left(\boldsymbol{t}_{1}, \mathrm{U} / \mathrm{Th}\right)$, resulting in the nested Equation 2.11. 


$$
t=\frac{f_{U T h}\left[\frac{\ln \left(f_{U T h}+10^{6} \lambda_{232} t_{1}\right)}{\lambda_{232}}+\frac{\frac{U}{T h}\left(137.88 f_{U} \frac{\ln \left(f_{U}+10^{6} \lambda_{238} t_{1}\right)}{\lambda_{238}}+\frac{\ln \left(1+10^{6} \lambda_{235} t_{1}\right)}{\lambda_{235}}\right)}{137.88 f_{U}+1}\right]}{10^{6}\left(f_{U T h}+\frac{U}{T h}\right)}
$$

In order to calculate the age with equations (2.11) or (2.10), the two proportionality functions introduced above have to be calculated in connection with $\boldsymbol{t}_{\boldsymbol{l}}$ values calculated with equations (2.9) or (2.8), respectively. The $\mathrm{f}_{\mathrm{U}}$ function of argument $\boldsymbol{t}_{1}$ was calculated using a Microsoft Excel spreadsheet, its in-built formula editor, and the Excel 4 macro language. The decay constants and their uncertainties are those recommended in Steiger and Jäger (1977), taken from Jaffey et al. (1971) and Le Roux and Glendenin (1963). The $\boldsymbol{t}_{1}$ approximated ages were calculated for $10 \mathrm{Ma}$ intervals according to formula (2.8) by iteratively modifying the $\mathrm{U} / \mathrm{Pb}$ ratios; the obtained ratios were then used to calculate the $\boldsymbol{t}$ value corresponding to each $\boldsymbol{t}_{1}$ value by iteratively zeroing out the expression

$$
137.88 \mathrm{e}^{\lambda_{238}}+\mathrm{e}^{\lambda_{235} \mathrm{t}}-138.88[1+1 /(\mathrm{U} / \mathrm{Pb})] \text {. }
$$

The iterations were performed with a macro routine in two successive precision steps until the residuals attained minimum absolute values or equalled zero. No constraints were exerted on the precision of the calculated values, using the nominal values of the Excel sheet (15 digits display, precision $10^{-16}$ ). The residuals of the iterations were typically below detection, but not exceeding $3 \cdot 10^{-13}$ for the expression iterated to derive $t$. The differ- ence between the $\boldsymbol{t}$ values and the corresponding expression (2.10) were then zeroed out by iterating $f_{U}$ in each equidistant $\boldsymbol{t}_{\boldsymbol{l}}$ value. The residuals of the iteration resulted in most cases below the detection limit of the software, with a maximum absolute value not exceeding $2.33 \cdot 10^{-11}$. The $\mathrm{f}_{\mathrm{U}}$ values thus obtained were regressed against $\boldsymbol{t}_{1}$ up to the value corresponding to $\mathrm{t}=4 \mathrm{Ga}, \boldsymbol{t}_{1} \approx 7560 \mathrm{Ma}$. The $\boldsymbol{t}_{1}$ interval was divided in four domains by a trial and error procedure and the $f_{U}$ function regressed to a fourth-order polynomial for each interval, yielding the regression coefficients and residuals in Fig. 1.

In a similar manner, the $\mathrm{U} / \mathrm{Pb}$ ratios were calculated by iteration for 25 particular U/Th ratios (Fig. 2) and $10 \mathrm{Ma} \boldsymbol{t}_{1}$ intervals up to $\mathrm{t}=4 \mathrm{Ga}$, by zeroing out the expression

$$
\begin{aligned}
& 138.88\left(\mathrm{e}^{\lambda_{232} \mathrm{t}}-1\right) /(\mathrm{U} / \mathrm{Th})+137.88 \mathrm{e}^{\lambda_{238^{\mathrm{t}}}}+\mathrm{e}^{\lambda_{235^{\mathrm{t}}}}- \\
& 138.88[1+1 /(\mathrm{U} / \mathrm{Pb})] .
\end{aligned}
$$

The $f_{\text {UTh }}$ values were then determined by iteratively cancelling the difference between the age equation and equation (2.11) for each of the U/Th ratios and $\boldsymbol{t}_{1}$ values. One may note from the graph in Fig. 2 that the coeval ages for different $\mathrm{U} / \mathrm{Th}$ ratios align along straight isochrons as expected, and the curves for increasing U/Th ratios tend to converge towards a limiting value. This limiting value

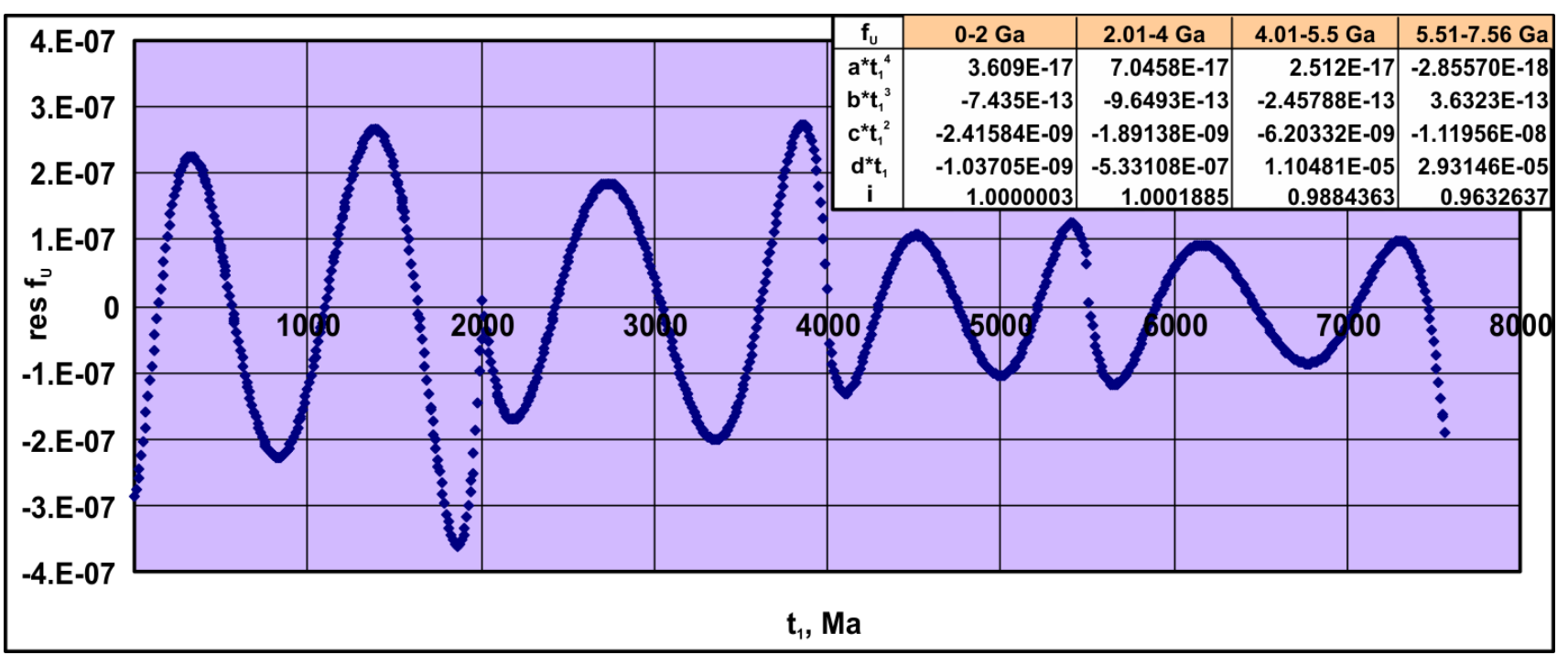

Fig. 1. The coefficients of the polynomial regression and associated residuals obtained for the function $f_{u}\left(t_{1}\right)$. Values rounded to number of digit displayed. 
(corresponding to $\mathrm{U} / \mathrm{Th} \rightarrow \infty$ ) resulted from extrapolating the $f_{\mathrm{UTh}}$ vs. $\boldsymbol{t}_{1}$ relationship along each 10 Ma-spaced isochron to the corresponding $\boldsymbol{t}_{1}$ value in the pure $\mathrm{U}-\mathrm{Pb}$ system. The corresponding function $\mathrm{f}_{\mathrm{UTh}}^{\mathrm{U}}\left(\boldsymbol{t}_{1}\right)$ was derived from polynomial regression of the individual $\mathrm{f}_{\text {UTh }}^{\mathrm{U}}$ values. The fourth order polynomial regression coefficients and the residuals of the $\mathrm{f}_{\mathrm{UTh}}^{\mathrm{U}}$ function calculated on three intervals are represented in Fig. 3.

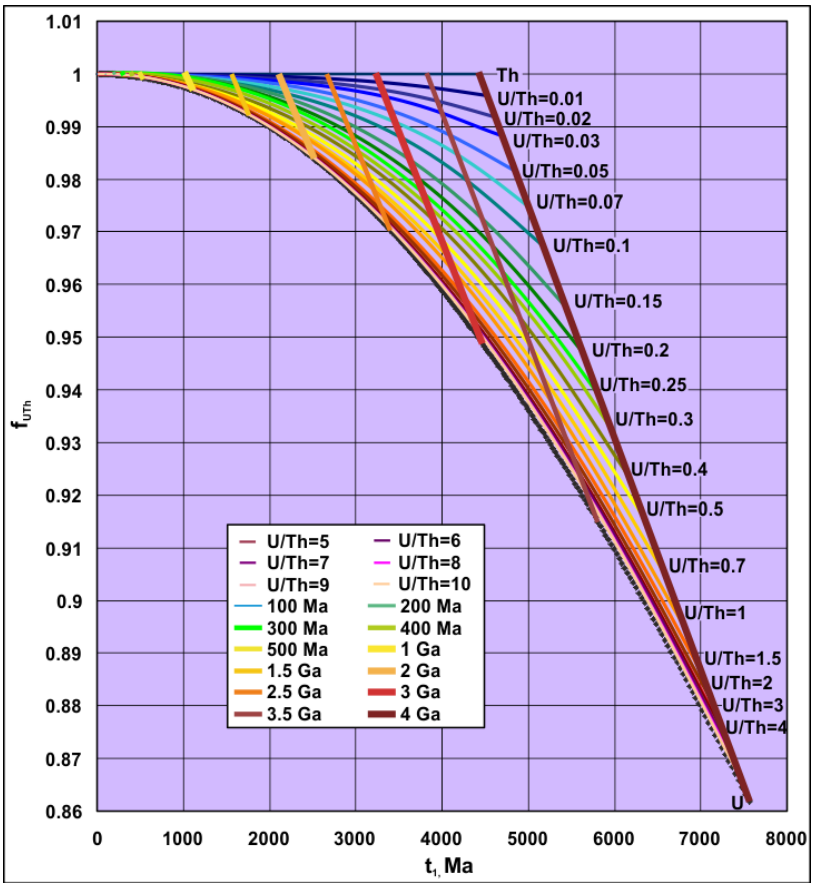

For each composition $i$, on the vertical line passing through a particular $\boldsymbol{t}_{1}$ two segments are defined, namely the distance from the abscissa of the intersections of $\mathrm{f}_{\mathrm{UTh}}^{\mathrm{i}}$ and $\mathrm{f}_{\text {UTh }}^{\mathrm{U}}$ respectively. The ratio of the two segments is a reciprocal function of U/Th when real-age $(\boldsymbol{t})$ values are considered, its inverse having thus a linear variation $v s$. $\mathrm{Th} / \mathrm{U}$ (Fig. 4A). In terms of $\boldsymbol{t}_{1}$, a systematic deviation from this relationship occurs (Fig. 4B), implying the necessity of data regression on restricted $\boldsymbol{t}_{1}$ (and sometimes also compositional) domains. The deviations are larger at low $\boldsymbol{t}_{1}$ values because of both the position of the points at the lower end of the $\mathrm{f}_{\mathrm{UTh}}^{\mathrm{U}}$ regression curve and unfavourable relative $v s$. absolute deviations ratio, but the quasi-reciprocal/quasi-linear relationship of the abovementioned ratio is maintained for each $t_{1}$ value (Fig. 4B). In age domains strongly affected by deviations, the regression of $f_{U T h}$ actually compensates for the errors of the $\mathrm{f}_{\text {UTh }}^{\mathrm{U}}$ regression.

For $\mathrm{U} / \mathrm{Th} \geq 2$, up to $\boldsymbol{t}_{1}=100 \mathrm{Ma}$, a linear relationship is apparent in Fig. 4A between the U/Th ratio and $\left(1-\mathrm{f}_{\mathrm{UTh}}\right) /\left(1-\mathrm{f}_{\mathrm{UTh}}^{\mathrm{U}}\right)(=$ segment ratio $)$ corresponding to each individual $\boldsymbol{t}_{1}$ age value, while for $\mathrm{U} / \mathrm{Th}<2$, the $\mathrm{Th} / \mathrm{U}$ ratio bears a linear relationship to the segment ratio, which is also maintained at older $t_{1}$ ages (Fig. 4B). The coefficients of the linear function

$\mathrm{f}(\mathrm{U} / \mathrm{Th})_{t I}=\left(1-\mathrm{f}_{\mathrm{UTh}}\right) /\left(1-\mathrm{f}_{\mathrm{UTh}}^{\mathrm{U}}\right)$

were calculated for each $\boldsymbol{t}_{\boldsymbol{l}}$ value up to the intersection with the $4 \mathrm{Ga}$ isochron. By regressing the linear coefficient and intercept of the segment ratio function of $\mathrm{U} / \mathrm{Th}$ against $1 / t_{1}$ over the intervals $\mathrm{U} / \mathrm{Th} \geq 2, \boldsymbol{t}_{1} \leq 100 \mathrm{Ma}$ one obtains:

Fig. 2. The futh vs. $\mathbf{t}_{1}$ graph plotted from iteration data.

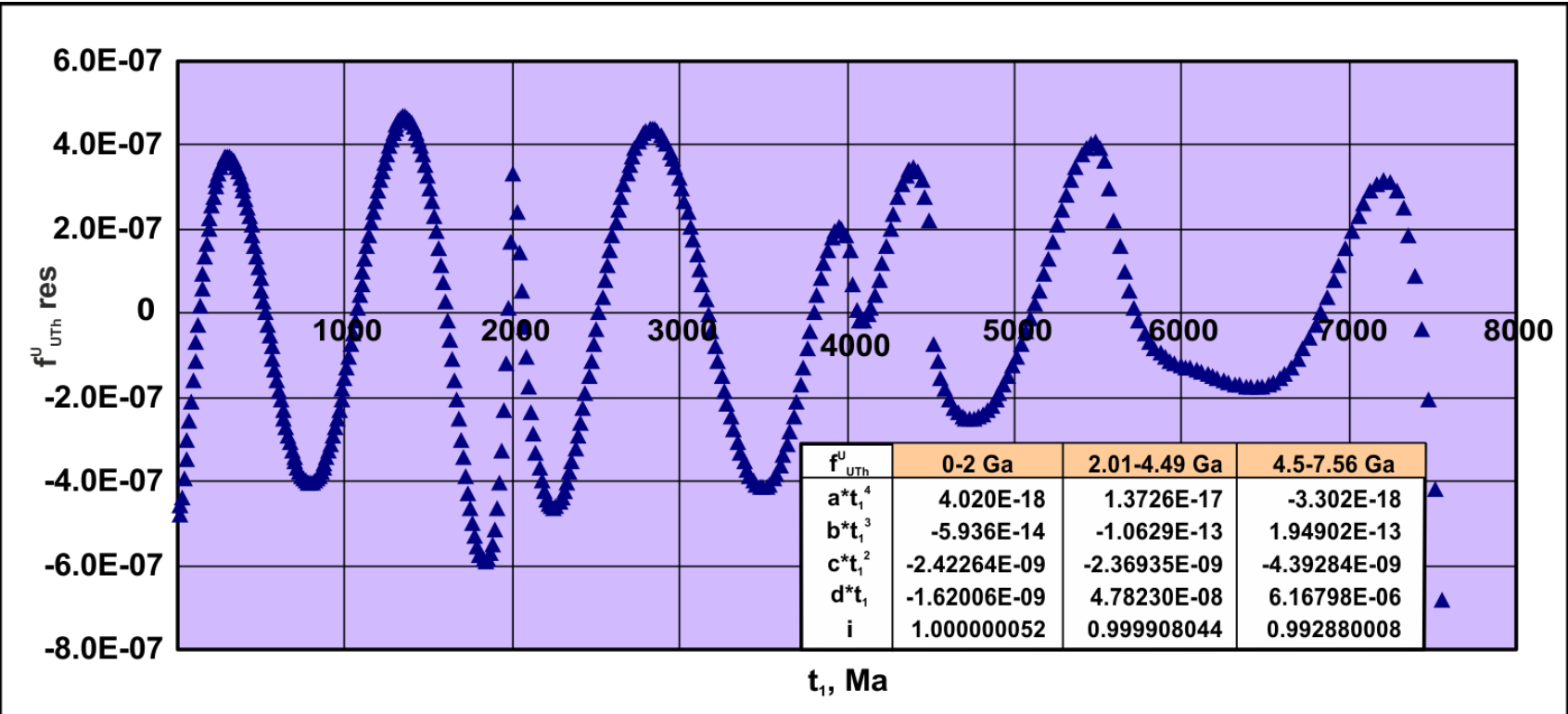

Fig. 3. The coefficients of the polynomial regression and associated residuals obtained for the function fU UTh $\left(\mathbf{t}_{1}\right)$. 
$\left(1-f_{U T h}\right) /\left(1-f^{U}{ }_{U T h}\right)=$

$\operatorname{pol}_{1}^{(2)}\left(1 / t_{1}\right) \cdot \mathrm{U} / \mathrm{Th}+\operatorname{pol}_{2}^{(2)}\left(1 / \boldsymbol{t}_{1}\right)$,

equivalent to:

$\mathrm{f}_{\mathrm{UTh}}=1-\left[(m \mathrm{U} / \mathrm{Th}+q) / \boldsymbol{t}_{1}^{2}+\right.$

$\left.(n \cdot \mathrm{U} / \mathrm{Th}+r) / \boldsymbol{t}_{1}+p \cdot \mathrm{U} / \mathrm{Th}+s\right] \cdot\left(1-\mathrm{f}_{\mathrm{UTh}}^{\mathrm{U}}\right)$,

where the parameters $m$ to $s$ represent the coefficients of second degree $\operatorname{pol}_{1}^{(2)}$ and $\operatorname{pol}_{2}{ }^{(2)}$ polynomial functions
(Fig. 5A, Appendix 1). In a similar way, for $\mathrm{U} / \mathrm{Th}>2$, $\boldsymbol{t}_{1}<300 \mathrm{Ma}$ and $\mathrm{U} / \mathrm{Th} \geq 2,100 \mathrm{Ma}<\boldsymbol{t}_{1} \leq 300 \mathrm{Ma}$ (Fig. 5B) the double regression of the segment ratio yields:

$\left(1-\mathrm{f}_{\mathrm{UTh}}^{\mathrm{U}}\right) /\left(1-\mathrm{f}_{\mathrm{UTh}}\right)=$

$\operatorname{pol}_{1}^{(3)}\left(1 / t_{1}\right) \cdot \mathrm{Th} / \mathrm{U}+\operatorname{pol}_{2}^{(3)}\left(1 / \boldsymbol{t}_{1}\right), \mathrm{f}_{\mathrm{UTh}}=$

$1-\left(1-\mathrm{f}_{\mathrm{UTh}}^{\mathrm{U}}\right) /\left\{[l /(\mathrm{U} / \mathrm{Th})+p] / \boldsymbol{t}_{1}{ }^{3}+[m /(\mathrm{U} / \mathrm{Th})+q] / \boldsymbol{t}_{1}{ }^{2}+\right.$

$\left.[n /(\mathrm{U} / \mathrm{Th})+r] / \boldsymbol{t}_{1}+o /(\mathrm{U} / \mathrm{Th})+s\right\}$,

see (Fig. 5).
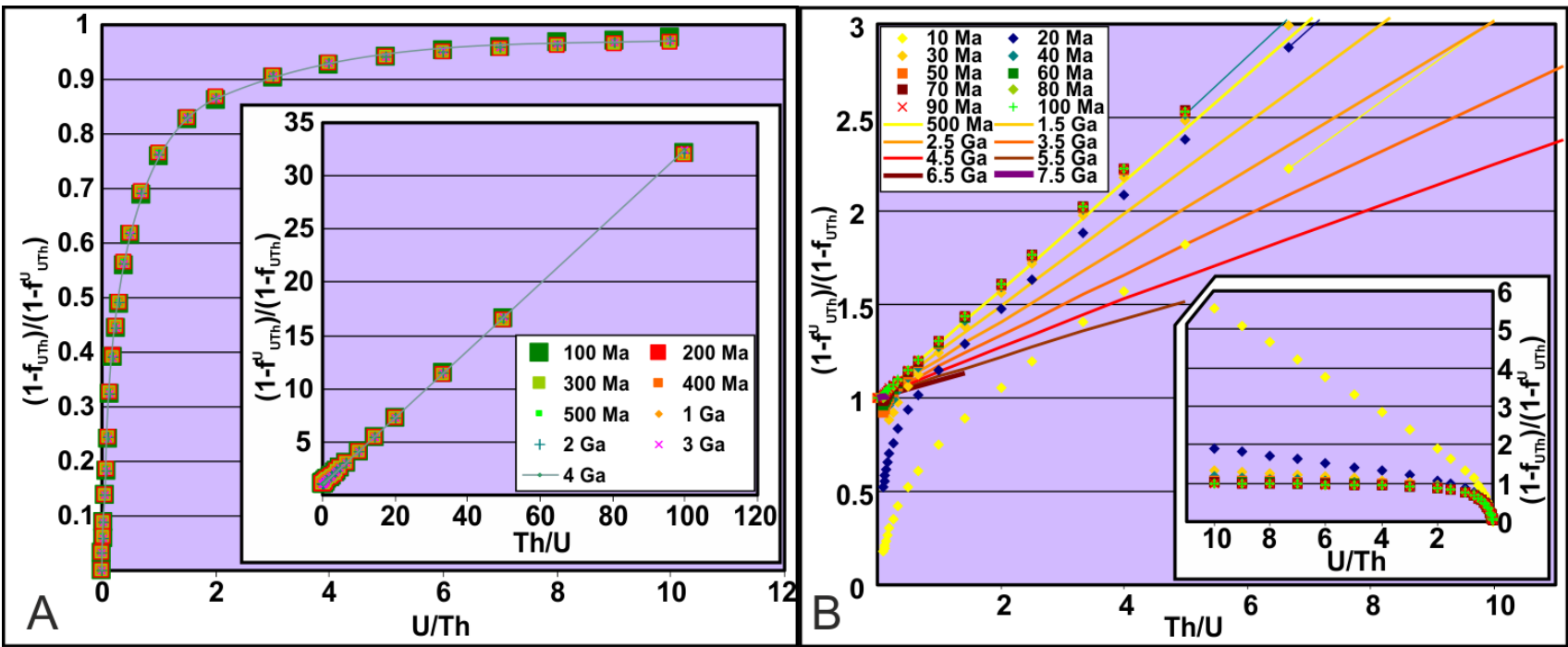

Fig. 4. Plots of the segment ratios as a function of parent element ratios: $A$ - at different iterated $\mathbf{t}$ values, $B$ - at different approximated $\mathbf{t}_{1}$ values.

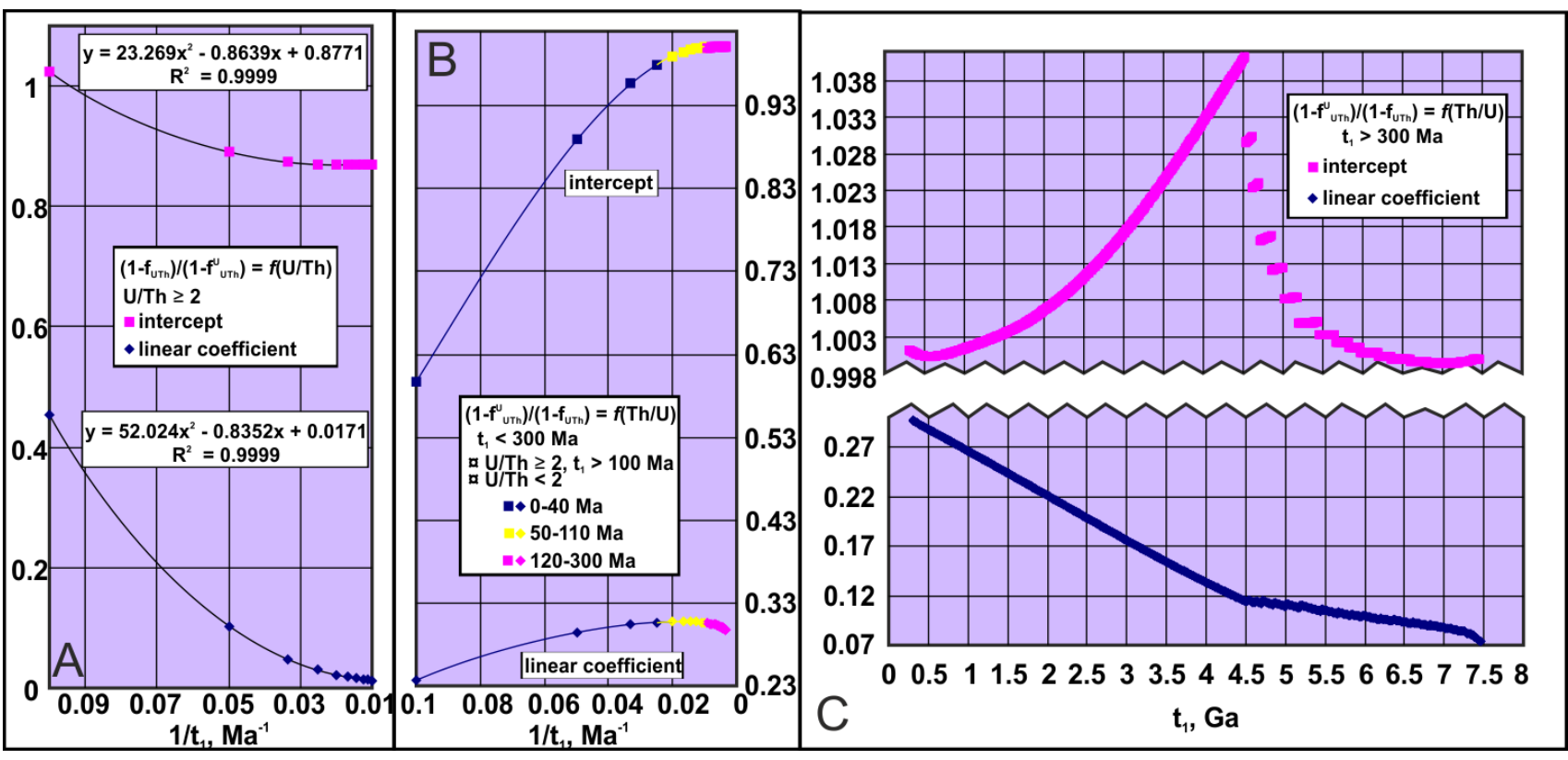

Fig. 5. The time-dependent variation of the linear coefficients of the segment ratios: $A-$ up to $100 \mathrm{Ma}$ for U/Th $\geq 2, B-$ up to $300 \mathrm{Ma}, \mathrm{C}-$ beyond $300 \mathrm{Ma}$. 
At $\boldsymbol{t}_{1}$ values greater than $300 \mathrm{Ma}$, the variation of $\mathrm{f}_{\mathrm{UTh}}$ is better described by:

$$
\begin{aligned}
& f\left(\mathrm{Th} / \mathrm{U}, \boldsymbol{t}_{1}\right)=\left(1-\mathrm{f}_{\mathrm{UTh}}^{\mathrm{U}}\right) /\left(1-\mathrm{f}_{\mathrm{UTh}}\right)= \\
& \operatorname{pol}_{1}{ }^{(2)}\left(\boldsymbol{t}_{1}\right) /(\mathrm{U} / \mathrm{Th})+\operatorname{pol}_{2}{ }^{(2-4)}\left(\boldsymbol{t}_{1}\right), \\
& \mathrm{f}_{\mathrm{UTh}}=1-\left(1-\mathrm{f}_{\mathrm{UTh}}^{\mathrm{U}}\right) /\left\{\left(o \boldsymbol{t}_{1}{ }^{4}\right)+\left(p \boldsymbol{t}_{1}{ }^{3}\right)+[l /(\mathrm{U} / \mathrm{Th})+q] \boldsymbol{t}_{1}{ }^{2}+\right. \\
& \left.[\mathrm{m} /(\mathrm{U} / \mathrm{Th})+r] \boldsymbol{t}_{1}+n /(\mathrm{U} / \mathrm{Th})+s\right\} .
\end{aligned}
$$

The $\boldsymbol{t}_{1}$-dependent linear coefficient and intercept of the $\mathrm{U} / \mathrm{Th}$ ratio, up to the intersection with the $\mathrm{t}=4 \mathrm{Ga}$ isochron, were determined by regression on three $\boldsymbol{t}_{1}$ intervals by a trial and error procedure, yielding a second order polynomial function of $\boldsymbol{t}_{1}$ for the linear coefficient of $\mathrm{Th} / \mathrm{U}$ and a fourth order polynomial for the intercept up to $1250 \mathrm{Ma}$, and then second order polynomials for both quantities on the intervals $1250-3250$ and 3250$4521.28 \mathrm{Ma}$. Beyond the intersection of the $4 \mathrm{Ga}$ isochron with the abscissa, the segment ratios were regressed against $\boldsymbol{t}_{1}$ for the compositional range lying left from the intersection with the isochron (Fig. 4), yielding a linear or second order polynomial time-dependent functions. The regressed coefficients (in electronic Appendix 4) are used to calculate the values of the $f_{U}$ and $f_{U T h}$ proportionality functions at particular $\mathrm{U} / \mathrm{Th}$ and $\boldsymbol{t}_{1}$ values, and the values of these functions are then replaced in equation (2.11) to obtain the explicitly approximated age. The precision of the approximation was checked for each $\mathrm{U} / \mathrm{Th}$ and $\boldsymbol{t}_{\boldsymbol{l}}$ value against the ages obtained by iteration and found to lie below $0.005 \mathrm{Ma}$ up to $\boldsymbol{t}_{1}=800 \mathrm{Ma}$, progressively increasing to higher values.
The quality of the linear regression of the segment ratio, as reflected in statistical parameters, tends to decrease at higher $\boldsymbol{t}_{1}$ ages (Fig. 6A); the statistics are more favourable for polynomial regressions of

$$
\left(1-\mathrm{f}_{\mathrm{UTh}}\right) /\left(1-\mathrm{f}_{\mathrm{UTh}}^{\mathrm{U}}\right)=f(\mathrm{U} / \mathrm{Th})_{\boldsymbol{t} 1}
$$

with increasing polynomial grade. The procedure outlined before was also used to regress each $\boldsymbol{t}_{1}$-dependent coefficient of U/Th for higher-order (up to 4) polynomial formulations of $f_{\mathrm{UTh}}\left(\boldsymbol{t}_{1}, \mathrm{U} / \mathrm{Th}\right)$. The residuals of the ages calculated using the derived coefficients measured against the iterated ages display a typical and constant pattern (Fig. 6B), namely a distorted sinusoid in the logarithmic plot, and record a coherent increase with $\boldsymbol{t}_{1}$ (Fig. 6C).

Therefore at each $\boldsymbol{t}_{1}$ age value the residuals allow a consistent compensation procedure of $\boldsymbol{t}$, which is a function of U/Th. For individual compositional domains on each residual plot, the compensation factor $c$ can be approximated by continuous functions of $\mathrm{U} / \mathrm{Th}$, such as polynomial or reciprocal functions of U/Th itself, or of its logarithm. A noteworthy case is represented by a sinusoidal function of the logarithm of the U/Th ratio suitable for intermediate compositions,

$\boldsymbol{c}=a \sin [b \ln (c \mathrm{U} / \mathrm{Th})]+d \mathrm{U} / \mathrm{Th}+e$,

where the $a$ to $e$ parameters adjust the amplitude, wavelength, horizontal offset, tilt (used rather as an exception) and vertical offset of the curve, respectively.

The choice of the polynomial order of $f_{\mathrm{UTh}}(\mathrm{U} / \mathrm{Th})_{t 1}$ over $\boldsymbol{t}_{\boldsymbol{l}}$ domains to determine the uncorrected age values, as well as the compensation function, represented a compromise between the simpler morphology of the age re-

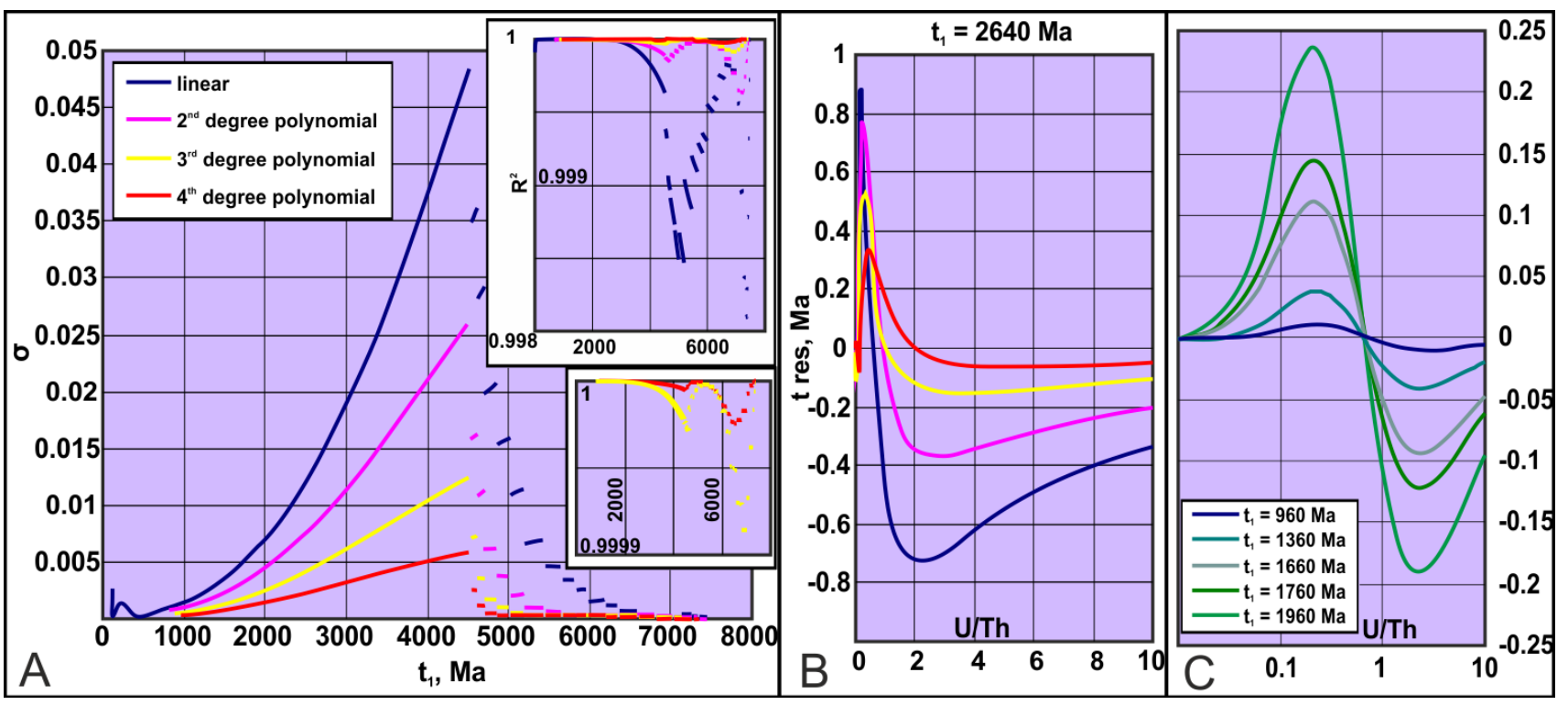

Fig. 6. The variation of statistical parameters and residuals for linear and up to $4^{\text {th }}$ grade polynomial regression of the segment ratio: $A-t h e$ standard error $(\sigma)$ variation vs. $t_{1}$; in insets plots of the squared correlation coefficients $\left(R^{2}\right)$ of the regressions, $B$ - the dependence of the residuals on the order of the regression, $\mathrm{C}$ - variation of the residuals of a linear regression with the estimated $\mathbf{t}_{1}$ time, logarithmic plot. 
siduals derived from the linear regression and the lower absolute values of those derived from higher-order polynomials. In the example illustrated in Fig. $7 \mathbf{A}$, in the compositional range $\mathrm{U} / \mathrm{Th}=0.01-0.05$, the compensation of the residuals was handled according to a polynomial curve

$$
a_{l}(\mathrm{U} / \mathrm{Th})^{2}+b_{l}(\mathrm{U} / \mathrm{Th})+c_{l}
$$

applied to the age estimate using the linear segment ratio function, in the range $\mathrm{U} / \mathrm{Th}=0.07-3$ a sinusoid

$a_{2} \sin \left[b_{2} \ln \left(c_{2} \mathrm{U} / \mathrm{Th}\right)\right]+d_{2}$

was applied to the age estimate using the fourth-order polynomial regression, and in the range $\mathrm{U} / \mathrm{Th}=4-10 \mathrm{a}$ polynomial curve

$$
a_{3}(\mathrm{U} / \mathrm{Th})^{2}+b_{3} \mathrm{U} / \mathrm{Th}+c_{3}
$$

was applied to the age estimate using the linear regression. Because of the low number of compositional points, and the greater interest embodied by the value of the residuals in each point than the overall statistical fit, the coefficients of the functions were derived at each $\boldsymbol{t}_{1}$ value by mathematical programming rather than by regression (Fig. 7B). The individual coefficients were automatically iterated until the alignment of the maximum and minimum values in the graph (see Fig. 7B) on the outer envelope of the residuals. The iteration consisted in successive cycles of aligning more distant points of the graph by modifying the higher order coefficients of the equation, followed by aligning closer-spaced points or equalization of the offsets between extreme points by modifying lower-order coefficients. The number of touching points in a graph equals the number of regulating parameters (coefficients of the particular equation) plus one. The initial parameters used in the optimization were set by forward extrapolation with increasing $\boldsymbol{t}_{1}$. Such an optimization was repeated at increasing $\boldsymbol{t}_{1}$ ages as far as the envelope of the residuals remained below 0.005 Ma, overstepping of this value being adjusted by changes in the equations and/or compositional ranges. Thus an $\mathrm{U} / \mathrm{Th}$-dependent compensation function was obtained at each $\boldsymbol{t}_{1}$, maintaining the explicit character and precision of the age expression, which was followed by the formulation and optimization of the compensation function over $\boldsymbol{t}_{\boldsymbol{1}}$ intervals.

The variation of the equivalent coefficients $a_{i}-d_{i}$ over $\boldsymbol{t}_{1}$ intervals allows itself to be fitted to second grade polynomials, linear equations, exceptionally constants and in one case a third degree polynomial over the entire $t$ range up to $4 \mathrm{Ga}$, on intervals of homogeneity of the previous data optimization procedures. The method used was also mathematical programming of the residuals, as exemplified in Fig. 8.

The age values resulting from calculation with the derived $\boldsymbol{t}_{1}$-dependent coefficients were checked in each sampling point and their residuals were found to lie within the $0.005 \mathrm{Ma}$ envelope, as in the case of the previous optimization of $\boldsymbol{c}=\boldsymbol{f}(\mathrm{U} / \mathrm{Th})$ at each $\boldsymbol{t}_{1}$ value.

All the derived parameters and formulae that employ them were stored in electronic Appendix 4, allowing calculation of the compensated radiometric ages $\boldsymbol{t}_{\mathrm{c}}=\boldsymbol{t}+\boldsymbol{c}$ directly from the chemical composition up to $4 \mathrm{Ga}$, at a
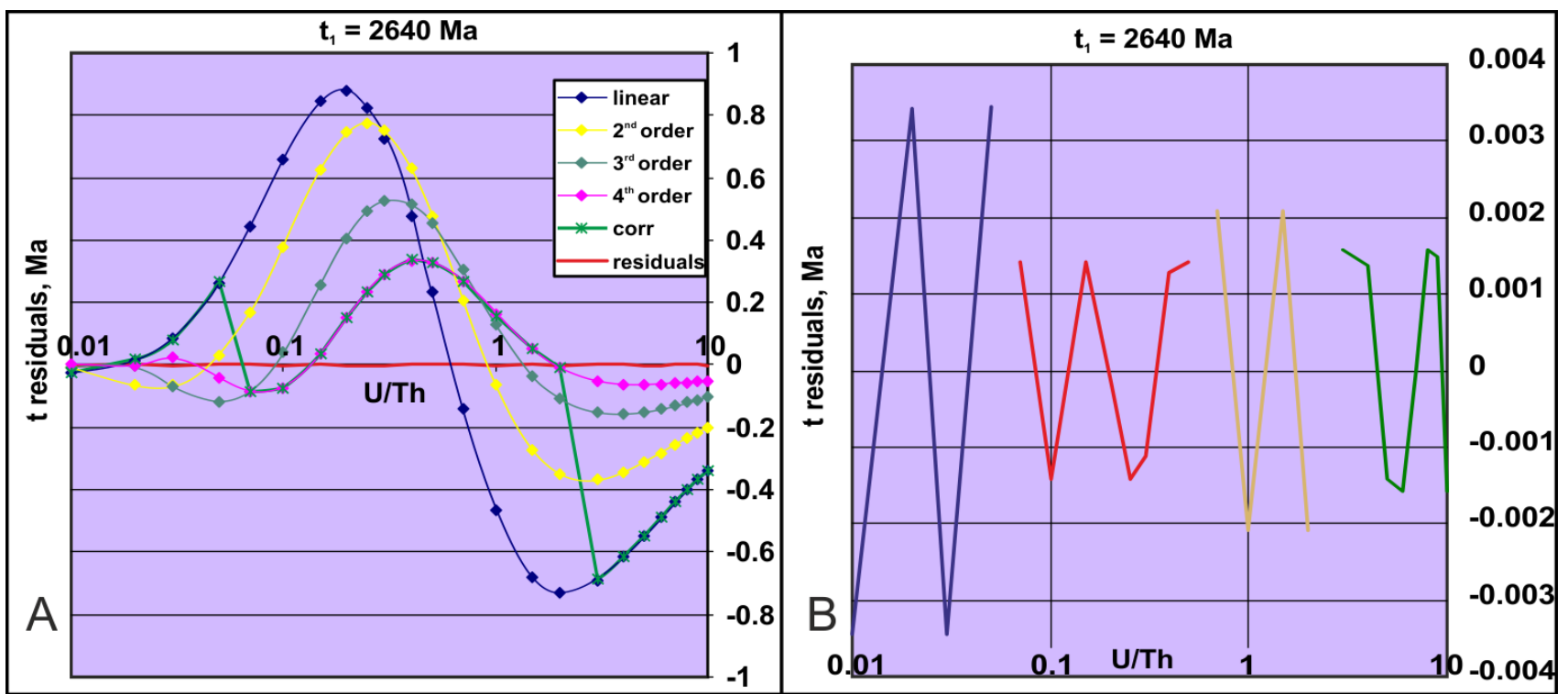

Fig. 7. Plot of the residuals applying equation (2.11) for age calculation and a U/Th-dependent compensation at a particular $\mathbf{t}_{1}$ value: $A-b$ before compensation, and choice of the correction functions (corr - linear approximation of the intersection ratio for U/Th $\leq 0.05$ and U/Th $\geq 3$, fourth order polynomial for $0.07 \leq U / T h \leq 2) B$ - after compensation on discrete compositional intervals (second order polynomial of UTh, three parameters and four intersections with the envelope of the residuals for U/Th $\leq 0.05$ and U/Th $\geq 3$; sinusoidal of logarithm, four parameters, five points on the envelope for $0.07 \leq U / T h \leq 0.5$; second order reciprocal, three parameters, four points on the envelope for $0.7 \leq U / T h \leq 2$ ). 


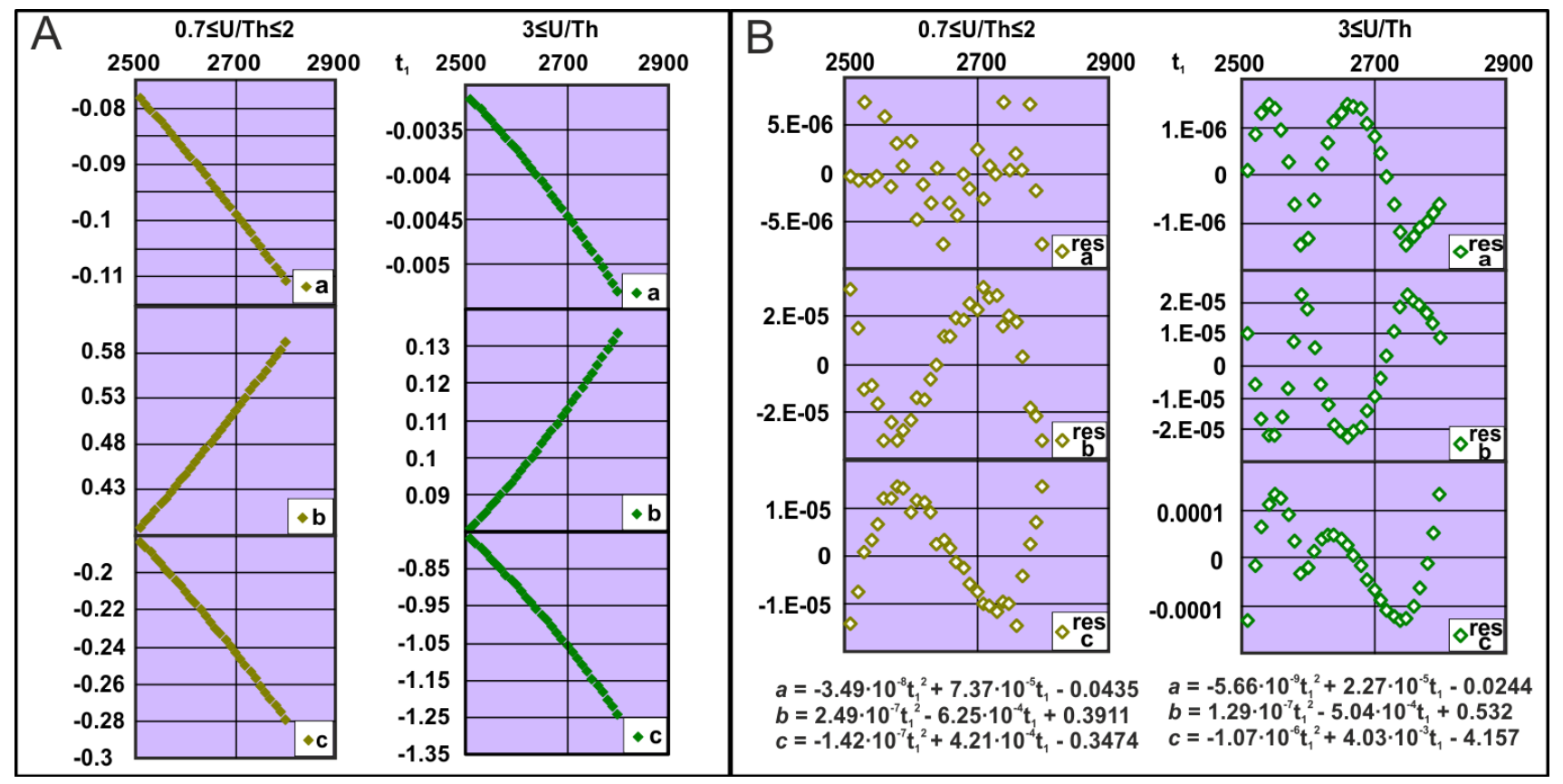

Fig. 8. Example of optimization of the time-dependent coefficients of the correction equation applied to calculated $\mathbf{t}$ values (on interval $2510-2800 \mathrm{Ma}$

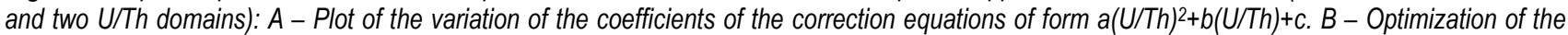
coefficients as second order polynomial functions of $\mathbf{t}_{1}$ by mathematical programming of the residuals (three parameters, four contact points on the envelope of the residuals); plot of the residuals and expression of the equations.

precision of $0.005 \mathrm{Ma}$, using an explicit formulation which allows tracking of the error propagation throughout all operations.

\section{LIMITS, INTERPOLATIONS AND EXTRAPO- LATIONS}

Because the determination of the formulae and coefficients outlined herein relies on iterative determination in discrete points and generalization of the derived parameters, as well as different types of optimization for different compositions and age domains, the problem of potential errors induced by sampling and boundary discontinuities cannot be disregarded.

In order to minimize the effect of discontinuities, the regressions of $\mathrm{f}_{\mathrm{U}}, \mathrm{f}^{\mathrm{U}}{ }_{\mathrm{UTh}}$ on each domain were calculated including points from the adjacent intervals, in order to ensure a smooth transition between domains. Inside the domains, the essential variables plot along continuous, smooth and well-defined curves, proving that the sampling of the iterated input data was representative. An exception to this general trend is represented by the variation of the residuals calculated with higher-order (3-4) $\mathrm{f}_{\mathrm{UTh}}(\mathrm{U} / \mathrm{Th})_{t_{1}}$ functions, and corresponding age formulations, which reveal poorly-resolved oscillations at very low U/Th ratios (Fig. 6B, 7A). For these compositional domains the segment ratio was approximated to the linear or second-order polynomial expressions and associated compensations were preferred. The optimization of the coefficients of the $\boldsymbol{t}_{1}$ polynomials representing the coefficients of the segment ratio functions may be extended at lower $\boldsymbol{t}_{1}$ ages, because the residuals tend to increase with age, therefore the intervals for the calculation of the ages were set open at the lower end and closed at the upper end. The most likely source of interpolation errors remains at the compositional boundaries where different age equations and compensation formulae were employed. In such cases, the compensations at the ends of the transition interval were interpolated normally if the same segment ratio function (and consequently $\mathrm{f}_{\mathrm{UTh}}$ formula) was employed, and in case of discordant boundaries involving different formulations of $\mathrm{f}_{\mathrm{UTh}}$ and different correction equations at the ends of the interval to be interpolated, rather the corrected boundary values were subject to interpolation. On that purpose, $\mathrm{f}_{\mathrm{UTh}}^{\mathrm{U}}, \boldsymbol{t}$, and corrections are calculated at both ends of the compositional interval, and the result is linearly interpolated.

\section{ESTIMATION OF THE ERRORS}

The error propagation through all stages of the age calculation and optimization was traced by quadratic summation, a basic and widespread procedure (e.g. Bevington and Robinson, 2003), applied stepwise for the successively calculated quantities. All covariance terms were considered to equal 0 , an assumption also made by Pyle et al. (2005) for the calculation of the standard deviations of the elemental k-ratios, and implicitly accepted in 
$\sigma_{t_{1}}=10^{-6} \sqrt{\left(\frac{\partial t_{1}}{\partial P b}\right)^{2} \sigma_{P b}^{2}+\left(\frac{\partial t_{1}}{\partial T h}\right)^{2} \sigma_{T h}^{2}+\left(\frac{\partial t_{1}}{\partial U}\right)^{2} \sigma_{U}^{2}+\left(\frac{\partial t_{1}}{\partial \lambda_{232}}\right)^{2} \sigma_{\lambda_{232}}^{2}+\left(\frac{\partial t_{1}}{\partial \lambda_{235}}\right)^{2} \sigma_{\lambda_{235}}^{2}+\left(\frac{\partial t_{1}}{\partial \lambda_{238}}\right)^{2} \sigma_{\lambda_{238}}^{2}}$

relevant literature (e.g. Lisowiec, 2006). The errors of the counting ratios directly propagate in the computation of element concentrations. The input standard errors of the measured elements are derived from the counting statistics during the microprobe analysis, recorded in the output of the probe and assumed to be corrected for identified up-stream systematic errors. Throughout the successive steps of error calculation, though covariance cannot be explicitly formulated, the correlation of the errors is accounted for during the recurrent emergence of some terms of the calculation and their associated errors.

The standard error of $\boldsymbol{t}_{1}$ expressed in Ma results by propagating the elemental and decay-constant errors through formula (2.9) and applying a proportionality coefficient (4.1).

The partial derivatives used in the formula are listed in Appendix 2. For the U-Pb-only system the standard error is calculated in a similar way starting from formula (2.8).

The standard errors of $\mathrm{f}_{\mathrm{U}}$ and $\mathrm{f}_{\mathrm{UTh}}^{\mathrm{U}}$, which are formulated as polynomial functions of $\boldsymbol{t}_{1}$, are calculated from the standard error of $\boldsymbol{t}_{1}$ by ignoring the comparatively negligible errors of the polynomial coefficients:

$\sigma_{\mathrm{f}_{\mathrm{U}}}=\left|4 a \boldsymbol{t}_{1}^{3}+3 b \boldsymbol{t}_{1}^{2}+2 c \boldsymbol{t}_{1}+d\right| \sigma_{\boldsymbol{t}_{\boldsymbol{I}}}$.

$\sigma_{\mathrm{U} / \mathrm{Th}}$ is calculated by propagating the standard errors of the two elements:

$\sigma_{U / T h}=\sqrt{\left(\frac{\sigma_{U}}{T h}\right)^{2}+\left(\frac{U}{T h^{2}}\right)^{2} \sigma_{T h}{ }^{2}}$

The standard error of $\mathrm{f}_{\mathrm{UTh}}=\boldsymbol{f}\left(\mathrm{f}_{\mathrm{UTh}}^{\mathrm{U}}, \boldsymbol{t}_{1}, \mathrm{U} / \mathrm{Th}\right)$ is calculated by propagating the standard errors of the three variables through the appropriate expression of $\mathrm{f}_{\mathrm{UTh}}$. For instance, given the $f_{U T h}$ equation using a fourth degree polynomial of $\boldsymbol{U} / \boldsymbol{T h}$,

$\mathrm{f}_{\mathrm{UTh}}=1-\left(1-\mathrm{f}_{\mathrm{UTh}}^{\mathrm{U}}\right) /\left[\left(a \boldsymbol{t}_{1}{ }^{3}+b \boldsymbol{t}_{1}{ }^{2}+c \boldsymbol{t}_{1}+d\right) /(\mathrm{U} / \mathrm{Th})^{4}+\right.$

$\left(e \boldsymbol{t}_{1}{ }^{2}+f \boldsymbol{t}_{1}+g\right) /(\mathrm{U} / \mathrm{Th})^{3}+\left(h \boldsymbol{t}_{1}{ }^{2}+i \boldsymbol{t}_{1}+j\right) /(\mathrm{U} / \mathrm{Th})^{2}+$

$\left.\left(k \boldsymbol{t}_{1}^{2}+l \boldsymbol{t}_{1}+m\right) /(\mathrm{U} / \mathrm{Th})+n \boldsymbol{t}_{1}{ }^{4}+o \boldsymbol{t}_{1}{ }^{3}+p \boldsymbol{t}_{1}{ }^{2}+q \boldsymbol{t}_{1}+r\right]$,

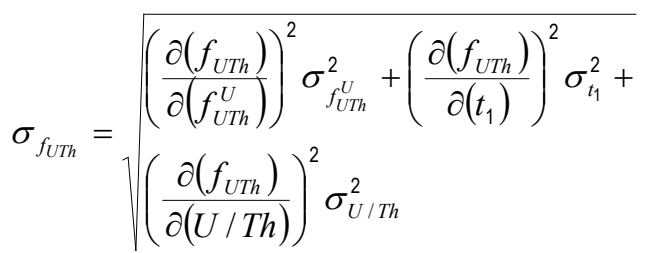

where:

$$
\begin{aligned}
& \partial\left(\mathrm{f}_{\mathrm{UTh}}\right) / \partial\left(\mathrm{f}_{\mathrm{UTh}}^{\mathrm{U}}\right)=1 /\left[\left(a \boldsymbol{t}_{1}{ }^{3}+b \boldsymbol{t}_{1}{ }^{2}+c \boldsymbol{t}_{1}+\right.\right. \\
& d) /(\mathrm{U} / \mathrm{Th})^{4}+\left(e \boldsymbol{t}_{1}{ }^{2}+f \boldsymbol{t}_{1}+g\right) /(\mathrm{U} / \mathrm{Th})^{3}+ \\
& \left(h \boldsymbol{t}_{1}{ }^{2}+i \boldsymbol{t}_{1}+j\right) /(\mathrm{U} / \mathrm{Th})^{2}+\left(k \boldsymbol{t}_{1}{ }^{2}+l \boldsymbol{t}_{1}+m\right) /(\mathrm{U} / \mathrm{Th})+ \\
& \left.n \boldsymbol{t}_{1}{ }^{4}+o \boldsymbol{t}_{1}{ }^{3}+p \boldsymbol{t}_{1}{ }^{2}+q \boldsymbol{t}_{1}+r\right], \\
& \partial\left(\mathrm{f}_{\mathrm{UTh}}\right) / \partial\left(\boldsymbol{t}_{1}\right)=\left(1-\mathrm{f}_{\mathrm{UTh}}^{\mathrm{U}}\right)\left\{4 n \boldsymbol{t}_{1}{ }^{3}+3\left[a /(\mathrm{U} / \mathrm{Th})^{4}+o\right] \boldsymbol{t}_{1}{ }^{2}+\right. \\
& 2\left[b /(\mathrm{U} / \mathrm{Th})^{4}+e /(\mathrm{U} / \mathrm{Th})^{3}+h /(\mathrm{U} / \mathrm{Th})^{2}+k /(\mathrm{U} / \mathrm{Th})+\right. \\
& p] \boldsymbol{t}_{1}+c /(\mathrm{U} / \mathrm{Th})^{4}+f /(\mathrm{U} / \mathrm{Th})^{3}+i /(\mathrm{U} / \mathrm{Th})^{2}+l /(\mathrm{U} / \mathrm{Th})+ \\
& q\}\left[\partial\left(\mathrm{f}_{\mathrm{UTh}}\right) / \partial\left(\mathrm{f}_{\mathrm{UTh}}^{\mathrm{U}}\right)\right]^{2},
\end{aligned}
$$

$\partial\left(\mathrm{f}_{\mathrm{UTh}}\right) / \partial(\mathrm{U} / \mathrm{Th})=\left(1-\mathrm{f}_{\mathrm{UTh}}^{\mathrm{U}}\right)\left[4\left(a \boldsymbol{t}_{1}{ }^{3}+b \boldsymbol{t}_{1}{ }^{2}+\right.\right.$

$\left.c \boldsymbol{t}_{1}+d\right) /(\mathrm{U} / \mathrm{Th})^{5}+3\left(e \boldsymbol{t}_{1}^{2}+f \boldsymbol{t}_{1}+g\right) /(\mathrm{U} / \mathrm{Th})^{4}+$

$2\left(h \boldsymbol{t}_{1}{ }^{2}+i \boldsymbol{t}_{1}+j\right) /(\mathrm{U} / \mathrm{Th})^{3}+\left(k \boldsymbol{t}_{1}{ }^{2}+l \boldsymbol{t}_{1}+\right.$

$\left.m) /(\mathrm{U} / \mathrm{Th})^{2}\right]\left[\partial\left(\mathrm{f}_{\mathrm{UTh}}\right) / \partial\left(\mathrm{f}_{\mathrm{UTh}}^{\mathrm{U}}\right)\right]^{2}$.

The corresponding expresion of $\mathrm{f}_{\mathrm{UTh}}$ and its partial derivatives for all of the alternative formulations of the $\mathrm{U} / \mathrm{Th}$ - and $\boldsymbol{t}_{1}$-dependence of the segment ratio are given in Appendix 1.

Propagating the errors of the arguments through equation (2.11), $\mathrm{t}=\boldsymbol{f}\left(\mathrm{f}_{\mathrm{U}}, \mathrm{f}_{\mathrm{UTh}}^{\mathrm{U}}, \boldsymbol{U} / \boldsymbol{T h}, \boldsymbol{t}_{1}\right)$,

$$
\begin{gathered}
\sigma_{t}=\left(\frac{\partial t}{\partial f_{U}}\right)^{2} \sigma_{f_{U}}^{2}+\left(\frac{\partial t}{\partial t_{1}}\right)^{2} \sigma_{t_{1}}^{2}+\left(\frac{\partial t}{\partial \lambda_{23 h}}\right)^{2} \sigma_{f_{U T h}}^{2} \sigma_{\lambda_{232}}^{2}+\left(\frac{\partial t}{\partial(U / T h)}\right)^{2} \sigma_{U / T h}^{2}+ \\
\left(\frac{\partial t}{\partial \lambda_{235}}\right)^{2} \sigma_{\lambda_{235}}^{2}+\left(\frac{\partial t}{\partial \lambda_{238}}\right)^{2} \sigma_{\lambda_{238}}^{2}
\end{gathered}
$$

and introducing proportionality factors to express the age in $\mathrm{Ma}$, the partial derivatives above are those given in Appendix 3. For the U-Pb system the errors are propagated instead through equation (2.10) in a similar manner.

The standard errors of the $\boldsymbol{t}_{1}$ and $\boldsymbol{U} / \boldsymbol{T} \boldsymbol{h}$ - dependent age corrections to be applied to the $t$ values are also calculated by quadratic summation

$$
\sigma_{c}=\sqrt{\left(\frac{\partial c}{\partial(U / T h)}\right)^{2} \sigma_{U / T h}^{2}+\left(\frac{\partial c}{\partial t_{1}}\right)^{2} \sigma_{t_{1}}^{2}} .
$$


In the case of corrections formulated as polynomial and reciprocal functions of $\boldsymbol{t}_{1}$ and $\boldsymbol{U} / \boldsymbol{T} \boldsymbol{h}$ the expression of the partial derivatives is trivial; for the expression

$\boldsymbol{c}=\operatorname{pol}_{1}\left(\boldsymbol{t}_{1}\right) \sin \left\{\operatorname{pol}_{2}\left(\boldsymbol{t}_{1}\right) \ln \left[\boldsymbol{U} / \boldsymbol{T h} \operatorname{pol}_{3}\left(\boldsymbol{t}_{1}\right)\right]\right\}+$

$\operatorname{pol}_{4}\left(\boldsymbol{t}_{1}\right) \mathrm{U} / \mathrm{Th}+\operatorname{pol}_{5}\left(\boldsymbol{t}_{1}\right)$

the partial derivatives are

$\partial c / \partial t_{1}=\left[\operatorname{pol}_{1}\left(\boldsymbol{t}_{1}\right)\right]^{\prime} \sin \left\{\operatorname{pol}_{2}\left(\boldsymbol{t}_{1}\right) \ln \left[\boldsymbol{U} / \boldsymbol{T h} \operatorname{pol}_{3}\left(\boldsymbol{t}_{1}\right)\right]\right\}^{+}$

$\operatorname{pol}_{1}\left(\boldsymbol{t}_{1}\right) \cos \left\{\operatorname{pol}_{2}\left(\boldsymbol{t}_{1}\right) \ln \left[\boldsymbol{U} / \boldsymbol{T h} \operatorname{pol}_{3}\left(\boldsymbol{t}_{1}\right)\right]\right\} \cdot$

$\left\{\left[\operatorname{pol}_{2}\left(\boldsymbol{t}_{1}\right)\right]^{\prime} \ln \left[\boldsymbol{U} / \boldsymbol{T h} \mathrm{pol}_{3}\left(\boldsymbol{t}_{1}\right)\right]^{+}\right.$

$\left.\operatorname{pol}_{2}\left(t_{1}\right)\left[\operatorname{pol}_{3}\left(\boldsymbol{t}_{1}\right)\right]^{\prime} / \operatorname{pol}_{3}\left(\boldsymbol{t}_{1}\right)\right\}+$

$\left[\operatorname{pol}_{4}\left(\boldsymbol{t}_{1}\right)\right]^{\prime} \mathrm{U} / \mathrm{Th}+\left[\operatorname{pol}_{5}\left(\boldsymbol{t}_{1}\right)\right]^{\prime}$

and

$\partial \boldsymbol{c} / \partial(\boldsymbol{U} / \mathbf{T h})=$

$\operatorname{pol}_{1}\left(\boldsymbol{t}_{1}\right) \cos \left\{\operatorname{pol}_{2}\left(\boldsymbol{t}_{1}\right) \cdot \ln \left[\operatorname{pol}_{3}\left(\boldsymbol{t}_{1}\right) \boldsymbol{U} / \mathbf{T h}\right]\right\} \cdot$

$\operatorname{pol}_{3}\left(\boldsymbol{t}_{1}\right) /(\boldsymbol{U} / \boldsymbol{T h})+\operatorname{pol}_{4}\left(\boldsymbol{t}_{1}\right)$.

The value of the age error is derived by quadratic summation of the errors of $\boldsymbol{t}$ and $\boldsymbol{c}$ over the continuity intervals of both $\boldsymbol{t}$ and $\boldsymbol{c}$ functions. In case $\boldsymbol{t}$ is formulated by the same $f_{U T h}$ equation at the ends of a discontinuity interval, the error is calculated by quadratic summation of the error terms corresponding to $\boldsymbol{t}$ and the interpolated $\boldsymbol{c}$ function.

Across boundaries with both discontinuous $\mathrm{f}_{\mathrm{UTh}}$ and $c$ formulations, two $t$ values are calculated at the ends of the interval $\left(\boldsymbol{t}_{\mathrm{h}}\right.$ and $\left.\boldsymbol{t}_{1}\right)$, and their compensation factors $\left(c_{\mathrm{h}}\right.$ and $\left.\boldsymbol{c}_{\mathrm{l}}\right)$ and:

$t_{c}=\left(t_{l}+c_{l}\right) \frac{\left(\frac{U}{T h}\right)_{h}-\frac{U}{T h}}{\left(\frac{U}{T h}\right)_{h}-\left(\frac{U}{T h}\right)_{l}}+\left(t_{h}+c_{h}\right) \frac{\frac{U}{T h}-\left(\frac{U}{T h}\right)_{l}}{\left(\frac{U}{T h}\right)_{h}-\left(\frac{U}{T h}\right)_{l}}$.

Because

$\frac{\frac{U}{T h}-\left(\frac{U}{T h}\right)_{l}}{\left(\frac{U}{T h}\right)_{h}-\left(\frac{U}{T h}\right)_{l}}=1-\frac{\left(\frac{U}{T h}\right)_{h}-\frac{U}{T h}}{\left(\frac{U}{T h}\right)_{h}-\left(\frac{U}{T h}\right)_{l}}$,

the expression above can be formulated:

$t_{c}=\left(t_{h}+c_{h}\right)-\frac{\left(\frac{U}{T h}\right)_{h}-\frac{U}{T h}}{\left(\frac{U}{T h}\right)_{h}-\left(\frac{U}{T h}\right)_{l}}\left[\left(t_{h}+c_{h}\right)-\left(t_{l}+c_{l}\right)\right]$

and its error is estimated according to the formula:

$$
\begin{aligned}
& \sigma_{t_{h}}^{2}+\sigma_{c_{h}}^{2}+\left(\sigma_{t_{h}}^{2}+\sigma_{c_{h}}^{2}+\sigma_{t_{l}}^{2}+\sigma_{c_{l}}^{2}\right)\left[\frac{\left(\frac{U}{T h}\right)_{h}-\frac{U}{T h}}{\left(\frac{U}{T h}\right)_{h}-\left(\frac{U}{T h}\right)_{l}}\right]^{2}+ \\
& \sigma_{t}= \\
& \sigma_{U / T h}^{2}\left[\frac{\left(t_{h}+c_{h}\right)-\left(t_{l}+c_{l}\right)}{\left(\frac{U}{T h}\right)_{h}-\left(\frac{U}{T h}\right)_{l}}\right]^{2}
\end{aligned}
$$

or alternatively:

$$
\sigma_{t}=\underbrace{}_{\sigma_{t_{l}}^{2}+\sigma_{c_{l}}^{2}+\left(\sigma_{t_{h}}^{2}+\sigma_{c_{h}}^{2}+\sigma_{t_{l}}^{2}+\sigma_{c_{l}}^{2}\right)\left[\frac{\frac{U}{T h}-\left(\frac{U}{T h}\right)_{l}}{\left.\left(\frac{U}{T h}\right)_{h}-\left(\frac{U}{T h}\right)_{l}\right]_{l}}\right.}\left[\begin{array}{l}
\sigma_{U / T h}^{2}\left[\frac{\left(t_{h}+c_{h}\right)-\left(t_{l}+c_{l}\right)}{\left(\frac{U}{T h}\right)_{h}-\left(\frac{U}{T h}\right)_{l}}\right]^{2}
\end{array}\right.
$$

The estimation of the error over the interpolated interval is more accurate using the boundary values closer to the actual $\mathrm{U} / \mathrm{Th}$ ratio, also resulting in a lower absolute value.

\section{ADDITIONAL ISSUES AND THE APPLICATION OF THE METHOD}

The correction functions and parameters derived by the procedure outlined above account for the random errors resulting from counting statistics, propagated from analyses to the calculated ages. The element concentrations are assumed to be accurate, as well as their standard errors. Therefore, detailed precautions in the choice of instrumental conditions and careful corrections are prerequisite to compensate for the mostly systematic errors encountered during the measurement (instrumental drift, matrix effect, background intensity, peak interferences). By their nature, systematic errors cannot be analysed statistically and need to be eliminated or corrected. A detailed account of these effects is given in Jercinovic and Williams (2005). As pointed out by Vlach (2010), Jercinovic et al. (2008), the most appropriate values for such corrections are machine-specific and have to be based on a careful calibrations of the analytical device and adequate use of standards. A partial exception to this generalization is the effect of peak interferences, which may be accounted for also after obtaining raw values of the element concentrations, once matrix and background issues have been addressed. The variation in the amplitude and position of peak overlaps shows a non-linear dependence on the instrumental conditions and element concentrations (Jercinovic and Williams, 2005), moreover, the best-fit curves for the interference of Th-lines on $\mathrm{U}$ and $\mathrm{Pb}$ do not pass through the origin of the correction factor $v s$. Th concentration graph. It could therefore be of 
advantage to devise relatively simple correction factors for specific analytical devices and mineral phases (e. $g$. monazite of confined Th contents), based on suitable standards, applied either on-line during the analysis, or on the analytical results.

The above-described explicit age expression is based on number of atoms, while the input data are primarily measured as element concentrations, which need to be converted in atomic concentrations or ratios by division by the atomic masses. For naturally occurring $\mathrm{U}$ and $\mathrm{Th}$ the atomic masses are known, but the atomic mass of $\mathrm{Pb}$ is unknown as it depends on the age and the relative concentration of the parent nuclides. A solution to this drawback is iterative data handling, using as initial input an approximation of the $\mathrm{Pb}$ atomic mass derived from the first-order Maclaurin approximation of the age:

$\mathrm{A}_{\mathrm{Pb}}=\left[\mathrm{Th} \cdot \lambda_{232} \cdot \mathrm{A}_{208 \mathrm{~Pb}}+\mathrm{U} / 138.88\right.$.

$\left.\left(137.88 \cdot \lambda_{238} \cdot \mathrm{A}_{206 \mathrm{~Pb}}+\lambda_{235} \cdot \mathrm{A}_{207 \mathrm{~Pb}}\right)\right] /$

$\left[\mathrm{Th} \cdot \lambda_{232}+\mathrm{U} / 138.88 \cdot\left(137.88 \cdot \lambda_{238}+\lambda_{235}\right)\right]$

and then reiterating the calculations with a more accurate estimate obtained from the resulting age:

$$
\begin{aligned}
& \mathrm{A}_{\mathrm{Pb}}=\left\{\mathrm { Th } \cdot \mathrm { A } _ { 2 0 8 _ { \mathrm { Pb } } } \left(\mathrm{e}^{\left.10^{6} \lambda_{232^{\mathrm{t}}}-1\right)+}\right.\right. \\
& \mathrm{U} / 138.88\left[\mathrm{~A} 206_{\mathrm{Pb}} \cdot 137.88 \cdot\left(\mathrm{e}^{10^{6} \lambda_{238 \mathrm{t}}}-1\right)+\right. \\
& \left.\left.\mathrm{A} 207 \mathrm{~Pb}\left(\mathrm{e}^{10^{6} \lambda_{235^{\mathrm{t}}}}-1\right)\right]\right\} /\left\{\mathrm{Th} \cdot \mathrm{A} 208_{\mathrm{Pb}} \cdot\left(\mathrm{e}^{10^{6} \lambda_{232} \mathrm{t}}-1\right)+\right.
\end{aligned}
$$

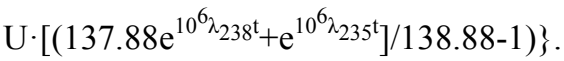

Practically the initial and the finally calculated atomic masses come into coincidence in the second iteration.

After recalculation of element concentrations in atomic concentrations a minor correction is required by the bias exerted on the analytical values by cross-measuring of the parent nuclides. Both ${ }^{234} \mathrm{U}$ and ${ }^{230} \mathrm{Th}$ belong to the decay series of ${ }^{238} \mathrm{U}$ and have half-lives longer than $5 \cdot 10^{4}$ years, needing to be subtracted from the total measured $\mathrm{U}$ and Th because they do not represent parent isotopes.

The atomic masses used for conversion to atomic concentrations are taken from Audi et al. (2003) and the isotopic bias is corrected using the isotopic abundances and half-lives of Cheng et al. (2000). The isotopic bias correction results in ages typically older by an order of magnitude of $0.01 \%$ as compared to uncorrected values, becoming relevant at high $U$ concentrations and older ages.

The calculation spreadsheet (Appendix 4, in Microsoft ${ }^{\circledR}$ Office Excel 2003 format) containing the parameters related to the explicit age equation has been set up as a in order to allow both storage of the derived data and actual calculation of mineral ages from microprobe data. The formulas have been inserted in cells to allow successive calculation of all the parameters discussed above and also of all the corrections related to the conversion of element concentrations and compositional biases.
A customized correction for peak interferences has been inserted to account for the overlap of Y L $\gamma$ and Th $\mathrm{M} \zeta$ on the $\mathrm{PbM} \alpha$ line, and of bulk Th high-order lines on UM $\beta$. The values have been calibrated by Thomas Theye (oral. comm.) for the Cameca SX100 microprobe in use and specific instrumental conditions at the Institute of Mineralogy and Geochemistry in Stuttgart. The correction can be disabled by setting the three mentioned factors to 0 if prior corrections already exist, or modified by replacing the default values with other customized correction factors.

Regarding the output values of the explicit formulation, the ages can be directly compared to those obtained by iteration, while for the associated errors there are no direct means of comparison. The age values disregarding the isotopic bias corrections reproduce the values obtained from iteration at the targeted precision level of $0.005 \mathrm{Ma}$ up to $4 \mathrm{Ga}$; the corrected values coincide closely, well inside the $1 \sigma$ interval.

The error estimates where checked against the few error sets determined by Monte Carlo simulation in literature (Lisowiec, 2006; Vlach, 2010 and personal comm.). Compared to the 60 approximately coeval and homogeneous analyses of Lisowiec (2006), the age errors determined by error propagation in the explicit formula amount a relative magnitude of 0.727 , with a standard deviation of 0.006 . Compared to a set of 12 analyses of Vlach (2010, written comm.), ranging from 300 Ma to $3 \mathrm{Ga}$, the relative magnitude is 0.89 , with a standard deviation of 0.14 . The calculated errors return larger values over interpolated intervals, typically by a few percent more that of the boundary values for the interpolation of both age values and corrections.

The method outlined here was devised to trace error propagation in data-point analyses assuming realistic estimates of the elemental errors. Its use in evaluating age populations corresponds to the "top-down" approach of Williams et al. (2006); nevertheless extending the statistical treatment over entire populations is beyond the scope of this paper, since the output data can be processed with existing very popular and powerful software (e. g. Ludwig, 1991 and more recent versions).

\section{ACKNOWLEDGEMENTS}

The idea of this contribution developed during a stay in Stuttgart in the framework of a partnership between the author's institution and Institut für Mineralogie und Krystallchemie in Stuttgart, sponsored by the Alexander von Humboldt Foundation. Hans Massonne is gratefully acknowledged for supporting the project and granting access to the facilities of the institute. Thomas Theye provided proficient and kind assistance with theoretical and practical analytical issues, friendly criticism and challenging discussions. Silvio Vlach and an anonymous reviewer significantly contributed to the improvement of an earlier submission of the manuscript, including detec- 
tion of some errors in the calculation spreadsheet. Ilya Adam kindly checked and improved the English of the paper. Financial support was provided from grant PN-IIID-PCE-2011-3-0030 by the Romanian Executive Unit for Financing Higher Education and Academic Research (UEFISCDI).

\section{APENDICES}

Appendices 1-3 as well as the Appendix 4 - the calculation spreadsheet (in Microsoft ${ }^{\circledR}$ Office Excel 2003 format) are available in electronic version of this article at http://dx.doi.org/10.2478/s13386-012-0007-3 as Supplementary Material.

\section{REFERENCES}

Audi G, Wapstra AH and Thibault C, 2003. The AME2003 atomic mass evaluation: (II). Tables, graphs and references. Nuclear Physics A 729(1): 337-676, DOI 10.1016/j.nuclphysa.2003.11.003.

Bosse V, Boulvais P, Gautier P, Tiepolo M, Ruffet G, Devidal JL, Cherneva Z, Gerdjikov I and Paquette JL, 2009. Fluid-induced disturbance of the monazite $\mathrm{Th}-\mathrm{Pb}$ chronometer: In situ dating and element mapping in pegmatites from the Rhodope (Greece, Bulgaria). Chemical Geology 261(3-4): 286-302, DOI 10.1016/j.chemgeo.2008.10.025.

Bevington PR and Robinson DK, 2003. Data Reduction and Error Analysis for the Physical Sciences, $3^{\text {rd }}$ Edition, McGraw-Hill, New York, $320 \mathrm{pp}$.

Cheng H, Edwards RL, Hoff J, Gallup CD, Richards DA, and Asmerom Y, 2000. The half-lives of uranium-234 and thorium-230. Chemical Geology 169(1-2): 17-33, DOI 10.1016/S0009-2541(99)001576.

Cherniak DJ, Bruce Watson E, Grove M and Harrison TM, 2004. Pb diffusion in monazite: A combined RBS/SIMS study. Geochimica et Cosmochimica Acta 68(4): 829-840.

Geyh MA and Schleicher H, 1990. Absolute age determination. Physical and chemical dating methods and their application. Springer Verlag, $514 \mathrm{pp}$.

Jaffey AH, Fynn KF, Glendenin LE, Bentley WC and Essling AM, 1971. Precision measurement of half-lives and specific activities of ${ }^{235} \mathrm{U}$ and ${ }^{238} \mathrm{U}$. Physical Review $C$ 4: 1889-1906, DOI 10.1103/PhysRevC.4.1889.

Jercinovic MJ and Williams ML, 2005. Analytical perils (and progress) in electron microprobe trace element analysis applied to geochronology: background acquisition interferences, and beam irradiation effects. American Mineralogist 90: 526-546.

Jercinovic MJ, Williams ML and Lane ED, 2008. In-situ trace element analysis of monazite and other fine-grained accessory minerals by EPMA Chemical Geology 254(3-4), 197-215, DOI 10.1016/j.chemgeo.2008.05.016.

Kato T, Suzuki K and Adachi M, 1999. Computer program for the CHIME age calculation. Journal of Earth and Planetary Sciences Nagoya Univ. 46: 49-56.

Le Roux LJ and Glendenin LE, 1963. Half-life of ${ }^{232} \mathrm{Th}$. Proceedings of National Meeting on Nuclear Energy, Pretoria, 83-94.

Lisowiec N, 2006. Precision estimation in electron microprobe monazite dating: Repeated measurements versus statistical (Poisson) based calculations. Chemical Geology 234(3-4): 223-235, DOI 10.1016/j.chemgeo.2006.04.010.

Ludwig KR, 1991. ISOPLOT: a plotting and regression program for rdiogenic-isotope data. U.S. Geological Survey Open-File Rep. 91445, $39 \mathrm{pp}$.

Montel JM, Veschambre M and Nicollet C, 1994. Datation de la monazite à la microsonde eléctronique. Comptes Rendues, Acadèmie des Sciences Paris 318: 1489-1495.

Montel J, Foret S, Veschambre M, Nicollet C and Provost A, 1996. Electron microprobe dating of monazite. Chemical Geology 131(14): 37-53, DOI 10.1016/0009-2541(96)00024-1.

Parrish RR, 1990. U-Pb dating of monazite and its application to geological problems Canadian Journal of Earth Sciences 27(11): 1431-1450, DOI 10.1139/e90-152.

Pyle JM, Spear FS, Wark DA, Daniel CG and Storm LC, 2005. Contributions to precision and accuracy of monazite microprobe ages. American Mineralogist 90: 547-577.

Rhede D, Wendt I and Förster H-J, 1996. A three-dimensional method for calculating independent chemical $\mathrm{U} / \mathrm{Pb}$ - and $\mathrm{Th} / \mathrm{Pb}$-ages of accessory minerals. Chemical Geology 130(3-4): 247-253, DOI 10.1016/0009-2541(96)00015-0.

Săbău G, 2009. CHIME U-Th-Pb - geochronology: an explicit age formulation as a function of element concentrations. Romanian Journal of Mineralogy 84: 68-71.

Scherrer NC, Engi M, Gnos E, Jakob V and Liecht A, 2000. Monazite analysis: from sample preparation to microprobe age dating and REE quantification, Schweizerische Mineralogische und Petrographische Mitteilungen 80: 93-105

Shields WR, 1960. Comparison of Belgian Congo and synthetic "normal" samples. Report. 8, National Bureau of Standards, Meeting of the Advisory Committee for Standard Materials and Methods of Measurement, May 17-18, 1960, 37 pp.

Slagstad T, 2006. Chemical (U-Th-Pb) dating of monazite: Analytical protocol for a LEO 1450VP scanning electron microscope and examples from Rogaland and Finnmark, Norway. NGU-Bulletin 443: 11-18

Steiger RH and Jäger E, 1977. Subcommission on Geochronology: Convention on the use of decay constants in geo- and cosmochronology. Earth and Planetary Science Letters 36(3): 359-362, DOI 10.1016/0012-821X(77)90060-7.

Suzuki K, Adachi M and Tanaka T, 1991. Middle Precambrian provenance of Jurassic sandstone in the Mino Terrane, central Japan: Th-U-total $\mathrm{Pb}$ evidence from an electron microprobe monazite study. Sedimentary Geology 75(1-2): 141-147, DOI 10.1016/00370738(91)90055-I.

Suzuki K, 2009. CHIME dating and age mapping of monazite in granulites and paragneisses from the Hwacheon area, Korea: implications for correlations with Chinese cratons. Geoscience Journal 13(3): 275-292

Suzuki K and Kato T, 2008. CHIME dating of monazite, xenotime, zircon and polycrase: protocol, pitfalls and chemical criterion of possibly discordant age data. Gondwana Research 14(4): 569-586, DOI 10.1016/j.gr.2008.01.005.

Vlach SRF, 2010. Th-U-Pb $\mathrm{T}_{\mathrm{T}}$ dating by electron probe microanalysis, part I. Monazite: analytical procedures and data treatment. Geologia USP, Série cientifica 10(1): 61-85.

Williams ML, Jercinovic MJ, Goncalves P and Mahan KH, 2006. Format and philosophy for collecting, compiling, and reporting microprobe monazite ages. Chemical Geology 225(1-2): 1-15, DOI 10.1016/j.chemgeo.2005.07.024

Williams ML, Jercinovic MJ, Harlov DE, Budzyń B and Hetherington CJ, 2011. Resetting Monazite Ages during Fluid-related Alteration. Chemical Geology 283(3-4): 218-225, DOI 10.1016/j.chemgeo.2011.01.019. 